\title{
Trovadores e jograis: mester de identidade sociocultural
}

\author{
Ana Luiza Mendes ${ }^{1}$
}

Resumo: O presente trabalho tem como objetivo analisar algumas cantigas da produção trovadoresca galego-portuguesa dos séculos XIII e XIV para compreender a relação existente entre trovadores e jograis no que diz respeito aos seus enfrentamentos em torno dos significados inerentes às designações de trovador e de jogral e como essas denominações contribuíram para a constituição de identidades culturais e sociais destes grupos tanto no ambiente cultural do movimento trovadoresco quanto no ambiente social dos reinos de Portugal e Castela. Dessa forma, também propõe-se a analisar as relações existentes entre as esferas da cultura e do poder no que diz respeito à utilização da produção trovadoresca como forma de legitimação do poder régio e como forma de transmissão de valores a ele relacionados.

Palavras-chaves: trovadorismo galego-português, trovador, jogral, identidades

Abstract: This paper aims to analyze some songs from GalicianPortuguese troubadour production of the thirteenth and fourteenth centuries to understand the relationship between troubadours and minstrels with regard to their confrontations around the meanings inherent in the names of trovador and jogral and how the names contributed to the creation of cultural and social identities of these groups on the cultural environment of the troubadour movement and the social environment of the kingdoms of Portugal and Castile. Thus, it is

${ }^{1}$ Doutoranda em História - UFPR. E-mail: analuizam982@gmail.com. 
also proposed to analyze the gaps between the spheres of culture and power in relation to the use of troubadour production as a way of legitimizing royal power and as a means of transmitting values pertinent to this relationship.

Keywords: Galician-Portuguese troubadour production, trovador, jogral, identities

Denomina-se trovadorismo o movimento poético-musical iniciado no século XI pelos trovadores da Provença, sul da França, cujas composições eram acompanhadas por instrumentos musicais e por dança, corroborando com o fato de que a literatura medieval não se restringia à escrita, não acessível a grande parte dos indivíduos, e fundamentava-se na oralidade, elemento que permitia a transmissão quase que imediata das informações que estas produções se revestiam, assim como da abrangência de um número maior de pessoas a receber tais elementos, sejam eles poéticos, amorosos, ideológicos, sociais, políticos e também de divertimento, uma vez que o verso se constitui como uma forma de ritmar a fala que contribui para o desenvolvimento da memória. ${ }^{2}$

Numa acepção mais ampla, o trovadorismo indica um grande circuito de produção e circulação poética e musical que atingia as esferas palaciana e "popular", abrangendo o ambiente rural e urbano.

\footnotetext{
${ }^{2}$ LOPES, Óscar; SARAIVA, António José. História da literatura portuguesa. Porto: Porto editora, 1955, p. 45.
} 
Numa acepção mais restrita, refere-se à poesia que circulava no meio cortesão entre os séculos XI e XIV, estendendo-se até o século XV em determinadas cortes da atual Alemanha. ${ }^{3}$

Percebe-se, pois que o trovadorismo constituiu-se em um movimento amplo e que uma das suas principais características, a itinerância, contribuiu para a sua expansão para diferentes regiões, transmitindo através de suas composições informações sobre diversas sociedades no que se refere aos acontecimentos políticos, sociais e também aos referentes aos sentimentos, como pode ser atestado na propagação da idealização do sentimento amoroso interligado com o ideal do comportamento cavaleiresco diante da dama: o amor cortês. Segundo Spina, o Amor é o primeiro grande tema inspirador da lírica, criada pelos trovadores provençais ${ }^{4}$, que transmitem, assim, o sentimento denominado fin'amors, o qual

se refere a um amor puro, perfeito, delicado, cujo desenrolar envolvia o frenesi provocado pelo erotismo e pelo controle do desejo, uma vez que cantava o amor ora inacessível, que não espera recompensa, apenas se submente totalmente à amada, com o compromisso de honrá-la e servi-la com fidelidade e discrição, ora carnal e adúltero. $\mathrm{O}$

\footnotetext{
${ }^{3}$ BARROS, José D'Assunção. A gaia ciência dos trovadores medievais. Revista de Ciências Humanas. Florianópolis, v. 41, n. 1 e 2. abril/out, 2007, p. 85. Disponível em: https://periodicos.ufsc.br/index.php/revistacfh/article/view/15623. Acesso em: $15 / 12 / 2014$.

${ }^{4}$ SPINA, Segismundo. A lírica trovadoresca. São Paulo: EDUSP, 1991.
} 
fin'amors era o modo próprio de amar, ou de se comportar perante o ser amado, da cortesia ${ }^{5}$

Ou seja, implicava no ideal de comportamento que deveria ser desenvolvido no ambiente cortês, que demandava, sobretudo, o refinamento dos costumes.

Este é um dos elementos legados pelos trovadores provençais que, entrando em contato com diferentes regiões, contribuíram para o desenvolvimento de outros movimentos poéticos de inspiração provençal. Assim, na atual Alemanha o fin'amors inspirou o minnesang; no Vale do Pó, o dolce stil nuovo; e na Península Ibérica o trovadorismo galego-português.

Sobre este último comumente aponta-se a sua gênese para o final do século XII, com uma cantiga de Paio Soares de Taveirós dedicada a Maria Pais Ribeiro, a Ribeirinha, favorita de Sancho I (11541211). Tal cantiga faz parte da lírica galego-portuguesa, compreendida como um grupo de cerca de 1680 textos de temática profana e 420 textos religiosos - as chamadas Cantigas de Santa Maria, de autoria de Afonso X, de Castela. ${ }^{6}$ Tais composições nos foram transmitidas por três cancioneiros manuscritos, a saber: Cancioneiro da Ajuda, contemporâneo das produções; Cancioneiro da Biblioteca Nacional e

\footnotetext{
${ }^{5}$ MENDES, Ana Luiza. O diálogo entre a razão e o pecado nas correspondências de Abelardo e Heloísa. São Paulo: Ixtlan, 2013, p. 49.

${ }^{6}$ GONÇALVES, Elsa; RAMOS, Maria Ana. A lírica galego-portuguesa. Lisboa: Editorial Comunicação, 1983, p. 18-19.
} 
Cancioneiro da Vaticana, datados do século XVI. O primeiro cancioneiro, redescoberto em 1823, é incompleto, compilando somente 310 cantigas de 38 autores, contendo, ainda, iluminuras dos personagens $\mathrm{e}$ instrumentos desse universo. O Cancioneiro $\mathrm{da}$ Biblioteca Nacional, também conhecido como Cancioneiro ColocciBrancuti, redescoberto em 1880, é o que conserva o maior número de composições (1560) e de autores e informações sobre estes. Além disso, neste cancioneiro está presente a Arte de Trovar, tratado poético fragmentário que nos legou certos conceitos pertinentes à norma da produção trovadoresca. Por fim, o Cancioneiro da Biblioteca da Vaticana, redescoberto em 1875, compreende os três gêneros: cantigas de amor, de amigo e de escárnio e maldizer, e incorpora alguns poetas e algumas composições que foram por algum motivo (social, estético, político) excluídos da recolha precedente.

No que diz respeito à Arte de Trovar, este é um nome dado modernamente ao fragmentário tratado de poética contido no Cancioneiro da Biblioteca Nacional, no qual tem-se as definições dos gêneros das composições, formas e normas das estruturas métricoestróficas, concordância verbal e tipos rítmicos. ${ }^{7}$ Assim, tem-se, por exemplo a definição de cantigas de amor e de amigo:

\footnotetext{
${ }^{7}$ Para mais informações sobre os Cancioneiros e o tratado poético vide: LANCIANI, Giulia; TAVANI, Giuseppe. Dicionário da literatura medieval galega e portuguesa. Lisboa: Caminho, 1993.
} 
E porque algũas cantigas i há em que falam eles e elas outrossi, per én é bem de entenderdes se som d'amor, se d'amigo: porque sabede que, se eles falam na prim<eir>a cobra* e elas na outra, <é d'>amor, porque se move a razon d'ele (como vos ante dissemos); e se elas falam na primeira cobra, é outrossi d'amigo; e se ambos falam em ũa cobra, outrossi é segundo qual deles fala na cobra primeiro. 8

Além desses dois gêneros há ainda o de escárnio e maldizer, além de outros que Tavani denomina como menores pois, "usufruem de uma estrutura temático-formal própria, autónoma" 9 , não se encaixando, dessa forma, nos gêneros acima citados. Tal tratado, portanto, nos oferece um diálogo didático entre teoria e prática, uma vez que a não adequação teórica na prática da composição das cantigas suscitaria motivos para que os seus artífices virassem mote de chacota nas cantigas de escárnio e maldizer.

A análise desse tratado poético e dessas composições são instigantes por nos forneceram elementos de extrema riqueza para a compreensão da sociedade medieval peninsular em seus variados aspectos, mas também nos suscitam questionamentos em torno da

\footnotetext{
${ }^{8}$ TAVANI, Giuseppe. Arte de Trovar do Cancioneiro da Biblioteca Nacional de Lisboa. Lisboa: Edições Colibri, 1999, p. 41.

* Estrofes. Termo designado na Arte de Trovar.

${ }^{9}$ TAVANI, Giuseppe. Trovadores e jograis. Lisboa: Caminho, 2002, p. 263.
} 
própria maneira de fazer tal análise, uma vez que tratando-se de poesia, o conteúdo desses textos perpassa por um componente simbólico, mas que não se restringe a isso, dado que este mantém relações com a realidade da qual emerge e para a qual se dirige.

Tal realidade social nos remete às influências do trovadorismo galego-português. Há vários autores que defendem a inter-relação entre os diferentes movimentos poéticos, dada a itinerância dos seus agentes. Assim, é possível identificar alguns elementos de origem andaluza, sobretudo no que diz respeito às cantigas de amigo, as quais teriam relações com as jarchas, composições líricas de autores anônimos produzidas entre os séculos XI e XIII que finalizam as muwassaha que, assim como as composições trovadorescas, remetiam ao universo feminino e eram cantadas diante de um público acompanhadas de instrumentos, como a flauta, o tambor e as castanholas. ${ }^{10}$

Além das composições andaluzas há o contato com a poesia provençal já mencionada. Os elementos provençais são identificados, sobretudo, nas cantigas de amor que, inclusive, são atestadas pelos próprios trovadores, como o rei Dom Dinis (1279-1325) que menciona os provençais em duas cantigas. ${ }^{11}$

\footnotetext{
${ }^{10}$ MENDES, Ana Luiza. A história que se faz cantiga nas barcarolas galegoportuguesas. São Paulo: Ixtlan, 2014, p. 122.

${ }^{11}$ Proençaes soen mui bem trobar e Quer' eu em maneira de proençal.
} 
O contato com os provençais ocorria desde o século VIII, mas pode-se afirmar que, em Portugal, a inter-relação tornou-se mais vívida com o futuro Afonso III (1248-1279), que viveu sete anos na corte de sua tia, Branca de Castela (1188-1252), em Bolonha. Com o seu retorno a Portugal para tomar o lugar de seu irmão, Sancho II (1209-1248), destronado,

começa o período de esplendor da lírica portuguesa. Favorecida pela confortável vida da corte, que se tornou possível em decorrência da maior segurança das relações políticas e sociais de Portugal, formouse uma sociedade de poetas que permaneceu durante o reinado dos dois monarcas seguintes e cujas obras, ao lado daquelas da época anterior, nos foram parcialmente conservadas em três cancioneiros manuscritos. ${ }^{12}$

Esta é, portanto, a realidade da qual se nutre o trovadorismo galego-português, cujo auge concentra-se entre os anos de 1252 e 1284, coincidindo com o reinado de Afonso III, estendendo-se no reinado de Dom Dinis em Portugal, e com o reinado de Afonso X (1252-1284) em Castela. Tal efervescência também coincide com a política de centralização monárquica empreendida nos dois reinos, a qual se estende à prática trovadoresca, uma vez que a ela também se estabelece

${ }^{12}$ LANG, Henry R. Cancioneiro d'el Rei Dom Denis e estudos dispersos. MONGELLI, Lênia Márcia; VIEIRA, Yara Frateschi (org.). Niterói: Editora da UFF, 2010, p. 78. 
uma hierarquia, como pode ser observado em Castela, em que é pedido a Afonso X a distinção hierárquica do ofício do trovador e do jogral:

Eu vos peço, não permitais que aqueles que possuem a arte verdadeira da intervenção, que têm o segredo dos versos, dos cânones e de outras belas poesias úteis, instrutivas, imortais, sejam chamados de jograis. Pois vós sabeis que sua obra é durável, ao contrário das futilidades dos outros. O prazer que proporcionam os músicos e os dançarinos só dura o instante em que os vemos e ouvimos. Mas os cantos dos bons trovadores, que sabem construir belas histórias, permanecem na lembrança e continuam a existir por muito tempo depois que seus autores cessaram de viver. É uma grande pena que tais pessoas não tenham uma denominação própria, ela qual possamos, nas cortes, distingui-los dos vis jograis. ${ }^{13}$

É identificável neste trecho a diferenciação de ofício entre o jogral e "aqueles que possuem a arte verdadeira". Diante disso há dois elementos importantes que podemos observar a partir da produção trovadoresca. $\mathrm{O}$ primeiro diz respeito à perceptível correlação entre as esferas do poder e da cultura. Num processo em que tanto o rei de Portugal quanto o de Castela visam diminuir o poder da nobreza, esta é mantida por perto, no paço trovadoresco, no qual o rei também é exposto a não só produzir, mas também ser alvo de cantigas, inclusive

\footnotetext{
${ }^{13}$ CLOUZOT, Martine. Um intermediário cultural no século XIII: o jogral. Signum. Belo Horizonte, v. 9, n. 7, 2005, p. 90.
} 
satíricas, nas quais fica nítido o que a nobreza pensa dele. Assim, o rei além de divertir a corte, se mantém consciente do que a agrada e, principalmente, do que desagrada. "Abrindo sua corte para a pluralidade e para uma livre expressão das tensões sociais, políticas e pessoais, o rei não pode evitar que ele mesmo se torne um alvo" ${ }^{\text {, }}$, como pode ser verificada nessa composição de Pai Gomes Charinho:

De quantas cousas eno mundo som nom vej'eu bem qual pod'en semelhar

a 'l-rei de Castela e de Leon

se[nom] úa qual vos direi: o mar.

O mar semelha muit'aqueste rei;

e daqui em deante vos direi

em quaes cousas, segundo razom.

O mar dá muit', e creede que nom

se pod'o mundo sem el governar, e pode muit', e [há] tal coraçom que o nom pode rem apoderar.

Des i ar [é] temudo, que nom sei quen'o nom tema; e contar-vos-ei ainda mais, e julga[de]-m'entom.

Eno mar cabe quant'i quer caber; e mantém muitos; e outros i há que x'ar quebranta e que faz morrer enxerdados; e outros a que dá

\footnotetext{
${ }^{14}$ BARROS, José D'Assunção. Afrontando o rei através da poesia - um estudo sobre as lutas de representações entre os trovadores medievais ibéricos dos séculos XIII e XIV. História e Perspectivas, Uberlândia, v. 34, jan./jun., 2006, p. 55. Disponível em: http://www.seer.ufu.br/index.php/historiaperspectivas/article/viewFile/19035/10234. Acesso em: 15/12/2014.
} 
grandes herdades e muit'outro bem.

E tod'esto que vos conto avém

a 'l-rei, se o souberdes conhocer.

E da mansedume vos quero dizer

do mar: nom há cont', e nunca será

bravo nem sanhudo, se lh'o fazer

outro nom fezer; e sofrer-vos-á

tôdalas cousas; mais se em desdém

o per ventura algum louco tem, com gram tormenta o fará morrer.

[E] estas manhas, segundo meu sem, que o mar há, há el-rei. E por en

se semelham, quen'o bem entender. ${ }^{15}$

Nesta cantiga, Charinho relaciona o mar, elemento vívido em suas composições devido à própria vivência de almirante-mor, com o rei Sancho IV de Castela (1284-1295). Da mesma forma que o mar o rei é responsável pela vida dos homens. Em alguns momentos tanto mar quanto rei podem ser generosos e em outros ambos podem acabar com a vida dos homens.

Porém, deixar tornar-se um alvo é sancionar a pluralidade trovadoresca, isto é, a diversidade dos seus artífices e intérpretes e legitima a política centralizadora do seu poder, pois traz a crítica ao

${ }^{15}$ Lopes. Graça Videira; FERREIRA, Manuel Pedro et al. Cantigas medievais galegoportuguesas [base de dados online]. Lisboa: Instituto de Estudos Medievais, FCSH/NOVA, 2011. Disponível em: http://cantigas.fcsh.unl.pt/cantiga.asp?cdcant=424\&tamanho=13\&semanotacoes=true. Acesso em 30/07/2014. 
local em que está sua mediação e controle, além de tomar conhecimento sobre quais são os pontos de tensão em seu reino.

$\mathrm{O}$ segundo elemento diz respeito ao pedido feito a Afonso X, citado anteriormente. Nele há a distinção entre aqueles que são iniciados, treinados, aperfeiçoados na arte trovadoresca e aqueles que não o são. Diante disso nos remetemos à hierarquia trovadoresca que assume na Península Ibérica um componente social bem marcado. Nela o trovador corresponde ao compositor de origem nobre que ocupa a posição superior nessa hierarquia. Por sua vez, o jogral posicionava-se numa escala inferior por ser um mero intérprete de canções alheias. A ele sobressaía o menestrel, músico-poeta protegido por um nobre. Seguindo-se a ele tem-se o segrel ${ }^{16}$, cavaleiro-trovador que andava de corte em corte. Além desses, também participavam do espetáculo trovadoresco as jogralescas e soldadeiras, dançarinas ou cantoras que em troca de dinheiro acompanhavam o jogral.

Diante disso, percebe-se que havia uma nítida distinção entre esses agentes trovadorescos e, mais importante, a consciência de que ela existia e, consequentemente, a identificação dentro dessa hierarquia cultural que também é funcional e social. "Esta feita sugere uma

\footnotetext{
${ }^{16}$ Esse termo foi utilizado para designar, no século XIII, o jogral que além de executar também compunha as cantigas, porém, não foi nesta acepção que o termo foi empregado pelos investigadores do assunto. Vide: LANCIANI, Giulia; TAVANI, Giuseppe. Dicionário da literatura medieval galega e portuguesa. Lisboa: Caminho, 1993, p. 609-611.
} 
transferência de valores. Ora, enquanto a centralização régia sugere uma reorganização do espaço social, a hierarquização dos integrantes do movimento trovadoresco sugere a organização do espaço cultural". ${ }^{17}$

A identificação, portanto, se dava por meio do reconhecimento da sua posição hierárquica dentro desse movimento, a qual estava relacionada com a sua função não só cultural como social. Saul António Gomes nos aponta uma ordenação de Hugo de São Vítor, na qual o cônego enuncia no seu Eruditions Didascaliae uma nova ordenação das ciências medievais. Ele profere sobre

uma área científica "mecânica" dividida em sete ciências. Uma delas é justamente a "teatrica scientia” (Livro Segundo, cap $^{\circ}$ XXVIII). Escreve Hugo de S. Vítor que essa "scientia” é: "a dos jogos que, pelo teatro, trazem ao povo o divertimento". [...] Da ciência teatral constava a récita de canções, de gestas, de elegias fúnebres ou de poemas laudatórios de pessoas vivas. Nos jogos lúdicos, para os quais toda a cidade devia possuir espaços próprios, o povo expandia as tensões acumuladas e reencontrava a alegria; o lúdico era, aliás, conveniente, ajudando a evitar opróbrios e crimes. ${ }^{18}$

Contudo, há que ressaltar que os jograis não formavam um grupo homogêneo. As diferenças variavam tanto em relação ao nível de

17 MENDES, Ana Luiza. A história que se faz cantiga nas barcarolas galegoportuguesas. São Paulo: Ixtlan, 2014, p. 40.

${ }^{18}$ GOMES, Saul António. Breves observações sobre jograis e cultura urbana na Coimbra medieval. Revista de História das Ideias, Coimbra, v. 19, 1997, p. 465-466. 
riqueza quanto ao mester escolhido: alguns eram especialistas em cantigas de amor, outros em cantigas de amigo; alguns tocavam cítola, outros eram mímicos. O que os unia era, de fato, a função social do divertimento propagado pelo movimento trovadoresco do qual eram integrantes.

Além do componente social e cultural os jograis também eram distinguidos pelo viés da moral. Este é o mote de uma análise desenvolvida por Martine Clouzot $^{19}$ que, a partir de fontes religiosas, avalia as diferentes facetas encarnadas pelo jogral que é utilizado por estas fontes como forma de demonstrar aos clérigos como não agir. Tanto fontes eclesiásticas quanto trovadorescas condenam a palavra do jogral. As primeiras condenam sob o ponto de vista de que "a tagarelice transforma o homem em bufão, em mímico, o reduz a jogral, degrada a dignidade da natureza humana" ${ }^{, 20}$. As segundas condenam a palavra do jogral porque ela não tinha valor estilístico.

A partir das críticas aos jograis é possível atestar que ele era, de fato, um importante agente social, pois encarnava diferentes facetas, revelando a heterogeneidade da sociedade medieval. No espetáculo trovadoresco apresenta-nos como um ser múltiplo, quase onipresente, pois pode ser compreendido como agente e como personagem. Como

${ }^{19}$ CLOUZOT, Martine. Um intermediário cultural no século XIII: o jogral. Signum. Belo Horizonte, v. 9, n. 7, 2005.

${ }^{20}$ Ibid., p. 71. 
agente porque participava ativamente do movimento trovadoresco e, juntamente com outras figuras sociais "encontrava nestes momentos poético-musicais a sua possiblidade de representação e um espaço para a ressonância de sua voz". ${ }^{21}$ Como personagem, o jogral aparece nas cantigas satíricas, nas quais o seu mester é colocado em dúvida:

Foi a cítola temperar

Lopo, que citolasse;

e mandarom-lh'algo dar,

em tal que a leixasse;

e el cantou log'entom,

e ar derom-lh'outro dom,

em tal que se calasse.

U a cítola temperou, logo lh'o dom foi dado, que a leixass', e el cantou;

e diss'um seu malado:

[- Pera leixar de cantar,] ar dê-lh'alg', a quem pesar:

nom se cal'endoado.

E conselhava eu bem a quem el dom pedisse, desse-lho log'e, per rem, seu cantar nom oísse, ca est'é, ai, meu senhor,

o jogral braadador

\footnotetext{
${ }^{21}$ BARROS, José D'Assunção. A prostituta como agente de circularidade no trovadorismo ibérico. (séculos XIII e XIV). Àrtemis, v. 2, jul, 2005, p. 58. Disponível em: http://periodicos.ufpb.br/ojs/index.php/artemis/article/view/2350. Acesso em: 15/12/2014.
} 
que nunca bom som disse. ${ }^{22}$

Esta é uma de quatro cantigas feitas por Martim Soares contra o jogral Lopo que, para o trovador português não emitia bons sons, ou seja, suas composições não eram de qualidade. O problema coloca-se aqui, não em relação à moralidade das suas ações, ponto abordado nas fontes religiosas, mas a qualidade do seu trovar que, como anteriormente mencionado, necessita certo grau de iniciação e aperfeiçoamento que, segundo os trovadores, os jograis não dominam. Dessa forma, podemos observar o estabelecimento de uma identidade cultural, mas que não foge de uma identidade social, uma vez que aos trovadores, nobres, é concebida a capacidade e a qualidade da ação poética que nas obras dos jograis, não nobres e que desempenhavam diferentes funções, os trovadores não reconheciam. Diante disso, percebe-se que havia uma necessidade por parte dos trovadores de se diferenciar perante os jograis. Esta diferenciação envolvia a ação trovadoresca propriamente dita, mas também poderia ser necessária pelo fato de que uma das formas de identificação de um jogral era a recompensa do seu mester, isto é, ele recebia pagamento pela sua performance, seja em moedas, panos ou alimentação. $\mathrm{O}$ mester do trovador talvez recebesse recompensa: um presente de uma dama. Há,

${ }^{22}$ Lopes. Graça Videira; FERREIRA, Manuel Pedro et al. Op. Cit. 
portanto, diferenciação moral e social nas formas de gratificação pelo ofício que, para um era uma necessidade e para outro divertimento o que leva ao imperativo de diferenciação e de afirmação de um sobre o outro.

Segundo José D’Assunção Barros, o trovadorismo foi um importante elemento no desenvolvimento da identidade palaciana, forjada a partir do jogo trovadoresco em que múltiplos atores se envolviam em uma complexa rede de inter-relações que perpassava pela mediação régia. ${ }^{23}$ Tal mediação faz sentido dentro do contexto da centralização política já mencionada e atrela-se ao fato de o próprio rei fazer-se integrante desse jogo. Não à toa, Dom Dinis, com 137 composições conhecidas, é o mais fecundo trovador português e considerado também o melhor por seus contemporâneos, como pode ser observada na seguinte cantiga:

Os namorados que trobam d'amor todos deviam gram doo fazer e nom tomar em si nem ũu prazer, por que perderam tam boo senhor como el rei dom Denis de Portugal, de que nom pode dizer nem ũu mal homem, pero seja posfazador.

\footnotetext{
${ }^{23}$ BARROS, José D'Assunção. O trovadorismo galego-português e o embate centralizador: encontros entre política e poesia nos primórdios medievais da construção nacional portuguesa. Revista Literatura e Debate, v.1, n.1, dez. 2007. Disponível em: http://revistas.fw.uri.br/index.php/literaturaemdebate/article/view/414. Acesso em: 15/12/2014.
} 
Os trobadores que pois ficarom eno seu regno e no de Leom, no de Castela, [e] no d'Aragon nunca pois de as morte trobarom. E dos jograres vos quero dizer: Nunc cobrarom panos nem aver E o seu bem muito desejarom. ${ }^{24}$

Este é um pranto $^{25}$ do jogral leonês Johan quando da morte do rei Dom Dinis. A composição testemunha o sentimento que será desencadeado pela ausência do rei-trovador que, além de ser um bom senhor e, por extensão, podemos acrescentar um bom rei, também foi um exímio trovador, cujo status jamais outro trovador atingiria, uma vez que o movimento trovadoresco português adentra em seu declínio a partir do desaparecimento do monarca. Na verdade, ocorre uma transformação nos parâmetros poéticos que culminaria na chamada poesia galego-castelhana que começa a despontar em meados do século XIV. A metamorfose se dá

quando um grupo de poetas que gravitavam em torno da corte castelhana do primeiros Trastâmaras

\footnotetext{
${ }^{24}$ ESTEVES, Elisa Nunes. O poeta D. Dinis. Congresso Internacional Dom Dinis. Disponível em: http://rdpc.uevora.pt/bitstream/10174/4207/1/Congresso\%20Internacional\%20Dom\% 20Dinis3.docx . Acesso em: 26/08/2012, p.3.

${ }^{25}$ Gênero lírico derivado do planh provençal, no qual se elogia uma pessoa de alta estirpe que morreu e que é, provavelmente, o protetor do poeta autor do pranto. Para maiores informações vide: LANCIANI, Giulia; TAVANI, Giuseppe. Op. Cit.
} 
(segunda metade do século XIV e início do XV) começavam a acolher - embora utilizando ainda (parcialmente e monotonamente) temas, fórmulas e tópicos residuais da tradição trovadoresca - as novidades provenientes de Itália, e preparava o advento, quer da ténue poesia palaciana quer da arte de Juan de Mena, de Santillana, dos Marique e do próprio Garcilaso. ${ }^{26}$

Antes disso, porém, lembremo-nos que o paço trovadoresco é o local onde o rei exerce sua função de mediação e controle das tensões sociais. Ao se lançar no meio do jogo ele está sujeito a críticas, nem sempre veladas. Esse também é um espaço de veiculação ideológica, no qual são transmitidos os valores culturais e sociais. A partir da cantiga do leonês Johan, podemos compreender que Dom Dinis conseguiu transmitir tais valores, pois além de ser um bom trovador também foi considerado um bom senhor.

A cantiga do jogral nos remete a outra característica deste movimento poético: o mundo trovadoresco não pertencia somente aos trovadores da Corte. Era composto também por

todos jograis e poetas-cantores - é portanto aquele em que toda a sociedade canta e é cantada: heróis e princesas, mas também meretrizes, ébrios, maridos traídos, impotentes, charlatões - todas as possibilidades individuais percorrem a gama de

\footnotetext{
${ }^{26}$ TAVANI, Giuseppe. Trovadores e jograis. Introdução à poesia medieval galegoportuguesa. Alfragide: Caminho, 2002, p. 20.
} 
cantigas trovadorescas. Mais ainda: todos os segmentos sociais - assoldadados, peões, cavaleiros, vilões, burgueses, infanções, ricos-homens atravessados por nuanças que vão da riqueza à penúria, todos os segmentos sociais são cantados e decantados uns pelos outros, o que ainda potencializa o número de combinações possíveis, já que o cavaleiro vilão visto por si mesmo não é aquele visto pelo jogral assoldadado ou pelo infanção empobrecido, pelo rei ou pelo trovador da nobreza tradicional. ${ }^{27}$

No trovadorismo galego-português é possível identificar, portanto, as dicotomias provenientes da vivência social do contexto do qual ele foi criado e para o qual retorna a partir de simbologias, ideologias e identidades veiculadas pelas cortes régias afim de difundir uma imagem de sabedoria e sofisticação ${ }^{28}$ que contribuem para a afirmação do poder régio. Além disso, a arena trovadoresca também contribuía para o entrelaçamento de múltiplos contextos sociais, para a manifestação das tensões sociais e para a produção de identidades sociais. Enquanto nas cortes provençais e alemãs as tenções giravam em

\footnotetext{
${ }^{27}$ BARROS, José D'Assunção. O trovadorismo galego-português e o embate centralizador: encontros entre política e poesia nos primórdios medievais da construção nacional portuguesa. Revista Literatura e Debate, v.1, n.1, dez. 2007. Disponível em: http://revistas.fw.uri.br/index.php/literaturaemdebate/article/view/414. Acesso em: 15/12/2014, p. 12.

${ }^{28}$ BARROS, José D'Assunção. A prostituta como agente de circularidade no trovadorismo ibérico. (séculos XIII e XIV). Àrtemis, v. 2, jul, 2005, p. 58. Disponível em: http://periodicos.ufpb.br/ojs/index.php/artemis/article/view/2350. Acesso em: 15/12/2014, p. 56.
} 
torno de questões estilísticas, nas cortes ibéricas o foco principal era de cunho social e político.

Por meio delas os trovadores-fidalgos depreciavam os jograis e segréis não-aristocratas, enquanto estes alardeavam uma igualdade trovadoresca em relação aos primeiros. Do mesmo modo, frações internobiliárquicas se digladiavam, linhagens se contrapunham, nobreza tradicional e nova nobreza emergente se entrechocavam nos contendores trovadorescos a sua representação poética. ${ }^{29}$

Assim, percebe-se que os jograis eram agentes socioculturais extremamente ativos nas cortes ibéricas e que contribuíam para a transmissão de valores culturais e sociais. Entretanto, eles encerram uma identidade ambígua, uma vez que eram assimilados no ambiente trovadoresco, seja ele as cortes régias, as cidades, as festas, mas eram, em certa medida, marginalizados por essa mesma atividade pela qual se inseriam na sociedade medieval ibérica. Tal marginalização ocorria através da necessidade de uma afirmação de identidade sociocultural. Os trovadores defendiam a sua identidade em contraposição à identidade do jogral que era aceita, mas menosprezada.

Entretanto, é possível verificar o vínculo existente entre trovadores e jograis: o da transmissão dos valores sociais, culturais e ideológicos da sociedade trovadoresca que possibilitou a multiplicidade

${ }^{29}$ Ibid, p. 59. 
de vozes que contribuíram para a apreensão de uma parcela extremamente rica da cultura medieval ibérica. Outro ponto em comum a trovadores e jograis era a fama. Através das disputas trovadorescas ambos os grupos se faziam conhecidos na arena trovadoresca. Além do mais, os jograis, devido à sua itinerância, contribuíam para a disseminação das cantigas entre as cortes ibéricas. O próprio rei Dom Dinis utilizou-se da sua habilidade poética para ganhar a fama de que trovava melhor que os provençais. Este foi um artifício retórico-poético, mas é possível que tenha corrido as cortes nas vozes dos jograis que cumpriram, assim, o papel de disseminadores de uma cultura poéticomusical, fazendo-se ouvir e cantando os feitos amorosos e políticos que a lírica galego-portuguesa testemunhou.

\section{Referências}

BARROS, José D’Assunção. O trovadorismo galego-português e o embate centralizador: encontros entre política e poesia nos primórdios medievais da construção nacional portuguesa. Revista Literatura $e$ Debate, v.1, n.1, dez. 2007. Disponível em: http://revistas.fw.uri.br/index.php/literaturaemdebate/article/view/414. Acesso em: 15/12/2014, p. 12.

- Afrontando o rei através da poesia - um estudo sobre as lutas de representações entre os trovadores medievais ibéricos dos séculos XIII e XIV. História e Perspectivas, Uberlândia, v. 34 , jan./jun., 2006.

Disponível em: 
http://www.seer.ufu.br/index.php/historiaperspectivas/article/viewFile/1 9035/10234. Acesso em: 15/12/2014.

A prostituta como agente de circularidade no trovadorismo ibérico. (séculos XIII e XIV). Àrtemis, v. 2, jul, 2005. Disponível em: http://periodicos.ufpb.br/ojs/index.php/artemis/article/view/2350. Acesso em: 15/12/2014

BASTOS, Douglas Santos. Os jograis como agentes culturais na medievalidade ibérica: séculos XIII e XIV. Roda da Fortuna Revista eletrônica sobre Antiguidade e Medievo. V. 2, n.1, 2013. Disponível em:

http://media.wix.com/ugd/3fdd18_abc3567be3542ee18a266f2fe8f784c 7.pdf. Acesso em: 01/08/2014.

CLOUZOT, Martine. Um intermediário cultural no século XIII: o jogral. Signum, número 7, 2005.

ESTEVES, Elisa Nunes. O poeta D. Dinis. Congresso Internacional Dom Dinis.

Disponível em: http://rdpc.uevora.pt/bitstream/10174/4207/1/Congresso\%20Internacion al\%20Dom\%20Dinis3.docx . Acesso em: 26/08/2012.

GOMES, Saul António. Breves observações sobre jograis e cultura urbana na Coimbra medieval. Revista de História das Ideias, Coimbra v.19, 1997.

GONÇALVES, Elsa; RAMOS, Maria Ana. A lírica galego-portuguesa. Lisboa: Editorial Comunicação, 1983.

LANCIANI, Giulia; TAVANI, Giuseppe. Dicionário da literatura medieval galega e portuguesa. Lisboa: Caminho, 1993. 
LANG, Henry R. Cancioneiro d'el Rei Dom Denis e estudos dispersos. MONGELLI, Lênia Márcia; VIEIRA, Yara Frateschi (org.). Niterói: Editora da UFF, 2010.

Lopes. Graça Videira; FERREIRA, Manuel Pedro et al. Cantigas medievais galego-portuguesas [base de dados online]. Lisboa: Instituto de Estudos Medievais, FCSH/NOVA, 2011. Disponível em: http://cantigas.fcsh.unl.pt/cantiga.asp?cdcant $=424 \& \operatorname{tamanho}=13 \&$ sema notacoes=true. Acesso em 30/07/2014.

LOPES, Óscar; SARAIVA, António José. História da literatura portuguesa. Porto: Porto editora, 1955.

MATTOSO, José (dir.). História de Portugal. A monarquia feudal (1096-1480). Lisboa: Editorial Estampa, 1997.

MENDES, Ana Luiza. A história que se faz cantiga nas barcarolas galego-portuguesas. São Paulo: Ixtlan, 2014.

- O diálogo entre a razão e o pecado nas correspondências de Abelardo e Heloísa. São Paulo: Ixtlan, 2013.

SANTOS, Dulce O. Amarante. Outros olhares sobre a jograria ibérica urbana (sécs. XIII-XIV). História Revista, 5 (1/2), jan/dez, 2000. Disponível em: http://www.revistas.ufg.br/index.php/historia/article/view/10590. Acesso em: 31/07/2014.

SERRÃO, Joaquim Veríssimo. História de Portugual. Estado, Pátria e Nação (1080-1415). Volume I. Lisboa: Editorial Verbo, 1979.

SPINA, Segismundo. A lírica trovadoresca. São Paulo: EDUSP, 1991.

TAVANI, Giuseppe. Trovadores e jograis. Introdução à poesia medieval galego-portuguesa. Alfragide: Caminho, 2002. 
Arte de Trovar do Cancioneiro da Biblioteca Nacional de Lisboa. Lisboa: Edições Colibri, 1999. 